\title{
One-Dimensional Gadolinium (III) Complexes Based on Alpha- and Beta-Amino Acids Exhibiting Field-Induced Slow Relaxation of Magnetization
}

\author{
Marta Orts-Arroyo, Adrián Sanchis-Perucho, Nicolas Moliner, Isabel Castro $\mathbb{D}^{\text {, Francesc Lloret }}$ \\ and José Martínez-Lillo *D
}

Citation: Orts-Arroyo, M.; Sanchis-Perucho, A.; Moliner, N.; Castro, I.; Lloret, F.; Martínez-Lillo, J. One-Dimensional Gadolinium (III) Complexes Based on Alpha- and Beta-Amino Acids Exhibiting Field-Induced Slow Relaxation of

Magnetization. Inorganics 2022, 10, 32. https: / / doi.org/10.3390/

inorganics10030032

Academic Editor: Akseli Mansikkamäki

Received: 8 February 2022

Accepted: 28 February 2022

Published: 3 March 2022

Publisher's Note: MDPI stays neutral with regard to jurisdictional claims in published maps and institutional affiliations.

Copyright: (C) 2022 by the authors. Licensee MDPI, Basel, Switzerland. This article is an open access article distributed under the terms and conditions of the Creative Commons Attribution (CC BY) license (https:// creativecommons.org/licenses/by/ $4.0 /)$.

\author{
Departament de Química Inorgànica, Instituto de Ciencia Molecular (ICMol), Universitat de València, \\ c/Catedrático José Beltrán 2, Paterna, 46980 València, Spain; marta.orts-arroyo@uv.es (M.O.-A.); \\ adrian.sanchis@uv.es (A.S.-P.); fernando.moliner@uv.es (N.M.); isabel.castro@uv.es (I.C.); \\ francisco.lloret@uv.es (F.L.) \\ * Correspondence: f.jose.martinez@uv.es; Tel.: +34-9635-44460
}

Abstract: Gadolinium (III) complexes exhibiting slow relaxation of magnetization are uncommon and have been much less studied than other compounds based on anisotropic lanthanide (III) ions. We prepared two one-dimensional gadolinium (III) complexes based on $\alpha$-glycine (gly) and $\beta$-alanine ( $\beta$-ala) amino acids, with the formula $\left\{\left[\mathrm{Gd}_{2}(\mathrm{gly})_{6}\left(\mathrm{H}_{2} \mathrm{O}\right)_{4}\right]\left(\mathrm{ClO}_{4}\right)_{6} \cdot 5 \mathrm{H}_{2} \mathrm{O}\right\}_{\mathrm{n}}(\mathbf{1})$ and $\left\{\left[\mathrm{Gd}_{2}(\beta-\right.\right.$ ala $\left.\left.)_{6}\left(\mathrm{H}_{2} \mathrm{O}\right)_{4}\right]\left(\mathrm{ClO}_{4}\right)_{6} \cdot \mathrm{H}_{2} \mathrm{O}\right\}_{\mathrm{n}}(2)$, which were magneto-structurally characterized. Compounds 1 and 2 crystallize in the triclinic system (space group P $\overline{1}$ ). In complex 1, two Gd (III) ions are eightcoordinate and bound to six oxygen atoms from six gly ligands and two oxygen atoms from two water molecules, the metal ions showing different geometries (bicapped trigonal prism and square antiprism). In complex 2, two Gd (III) ions are nine-coordinate and bound to seven oxygen atoms from six $\beta$-ala ligands and two oxygen atoms from two water molecules in the same geometry (capped square antiprism). Variable-temperature dc magnetic susceptibility measurements performed on microcrystalline samples of $\mathbf{1}$ and $\mathbf{2}$ show similar magnetic behavior for both compounds, with antiferromagnetic coupling between the Gd (III) ions connected through carboxylate groups. Ac magnetic susceptibility measurements reveal slow relaxation of magnetization in the presence of an external dc field in both compounds, hence indicating the occurrence of the field-induced singlemolecule magnet (SMM) phenomenon in both $\mathbf{1}$ and $\mathbf{2}$.

Keywords: amino acids; glycine; $\beta$-alanine; gadolinium; metal complexes; crystal structure; magnetic properties; single-molecule magnet

\section{Introduction}

Since the discovery of the mononuclear phthalocyanine-based lanthanide (III) complexes, which exhibit the single-molecule magnet (SMM) phenomenon, in 2003 [1,2], many efforts have focused on the synthesis and development of lanthanide(III)-based complexes in order to study this singular magnetic behavior, which allows SMMs to become promising candidates for potential applications in high-density data storage, quantum computing, molecular refrigeration and spintronics investigations [3-8].

Heterometallic 3d-4f mixed systems, radical bridged compounds, mono- and polynuclear lanthanide (III) complexes containing highly anisotropic $4 \mathrm{f}$ ions, mainly Dy (III) and to a lesser extent $\mathrm{Tb}$ (III), Ho (III) and Er (III), were investigated during the last two decades in the field of molecular magnetism [9-17]. More recently, mononuclear SMMs, also known as single-ion magnets (SIMs), based on dysprosium metallocenes were reported displaying energy barriers of magnetization reversal exceeding the $1500 \mathrm{~cm}^{-1}$ value and blocking temperatures as high as that of the liquid nitrogen $(>77 \mathrm{~K})$, which exemplify the current progress in this research area [18,19]. 
In comparison with other members of the lanthanides family, the Gd (III) ion has been largely ignored in this type of study. This metal ion is considered magnetically isotropic due to the half-occupied $4 \mathrm{f}^{7}$ electron configuration and the lack of orbital contribution $(\mathrm{S}=7 / 2, \mathrm{~L}=0)$ with an ${ }^{8} \mathrm{~S}_{7 / 2}$ ground state and a spherical quadrupole moment. Hence, the number of reported $\mathrm{Gd}$ (III) complexes that exhibit slow relaxation of magnetization is quite scarce $[20,21]$. Nevertheless, in some cases, Gd (III) cations show a very low or negligible value of the zero-field splitting $(D)$, which induces the occurrence of ac signals for complexes of this quasi-isotropic $4 \mathrm{f}$ metal ion. In this way, when an external magnetic field is applied, the degeneracy between energy levels can be removed and the Quantum Tunnelling of Magnetisation (QTM) can be suppressed, which could result in mixed mechanisms of spin-lattice, spin-phonon and spin-spin relaxations [20]. This fact makes this type of study on both new and old Gd(III) systems very appealing.

Herein, we report the synthesis, crystal structure and magnetic properties of two carboxylate-bridged $\mathrm{Gd}^{\mathrm{III}} 1 \mathrm{D}$ coordination polymers of the formula $\left\{\left[\mathrm{Gd}_{2}(\mathrm{gly})_{6}\left(\mathrm{H}_{2} \mathrm{O}\right)_{4}\right]\right.$ $\left.\left(\mathrm{ClO}_{4}\right)_{6} \cdot 5 \mathrm{H}_{2} \mathrm{O}\right\}_{\mathrm{n}}(\mathbf{1})$ and $\left\{\left[\mathrm{Gd}_{2}(\beta \text {-ala })_{6}\left(\mathrm{H}_{2} \mathrm{O}\right)_{4}\right]\left(\mathrm{ClO}_{4}\right)_{6} \cdot \mathrm{H}_{2} \mathrm{O}\right\}_{\mathrm{n}}(2)$ [gly $=\alpha$-glycine and $\beta$-ala $=\beta$-alanine $]$. To the best of our knowledge, no magneto-structural study on homometallic gadolinium (III) complexes based on these amino acids has been reported so far (Scheme 1).

A)<smiles>NCC(=O)O</smiles>

B)<smiles>NCCC(=O)O</smiles>

Scheme 1. Molecular structure of the amino acids $\alpha$-glycine (A) and $\beta$-alanine (B).

\section{Results and Discussion}

\subsection{Synthetic Procedure}

Compounds $\mathbf{1}$ and $\mathbf{2}$ are prepared from a mixture of $\mathrm{Gd}_{2} \mathrm{O}_{3}$ and glycine (1)/ $\beta$-alanine (2). Both mixtures react in an aqueous solution acidulated with perchloric acid. However, the employed crystallization technique was different. While for preparing 1 the reaction mixture was heated at $80{ }^{\circ} \mathrm{C}$ for $48 \mathrm{~h}$ and then cooled at a rate of $4.5^{\circ} \mathrm{C} / \mathrm{h}$ to room temperature, the reaction mixture that generates compound 2 was heated at $60^{\circ} \mathrm{C}$ for $1 \mathrm{~h}$ and the resulting solution was left to evaporate at room temperature for 2 weeks. It is important to mention that, although no problems were encountered in this work, care should be taken when using the potentially explosive perchlorate anion $\left(\mathrm{ClO}_{4}{ }^{-}\right)$, which comes from the perchloric acid.

\subsection{Description of the Crystal Structures}

Crystal data and structure refinement parameters for $\mathbf{1}$ and $\mathbf{2}$ are summarized in Table 1, where we indicate that both compounds crystallize in the triclinic system with centrosymmetric space group P $\overline{1}$. A recent review of the Cambridge Structural Database (CSD) revealed that the crystal structures of $\mathbf{1}$ and $\mathbf{2}$ were previously deposited with identifiers UKIKIJ and TEHKUN, respectively. Nevertheless, they were collected at room temperature and were deposited with refinement and resolution levels lower than the ones reported in this work [22,23].

The crystal structures of $\mathbf{1}$ and $\mathbf{2}$ are better described as cationic dinuclear $\left[\mathrm{Gd}^{\mathrm{III}}{ }_{2}\right]^{6+}$ units which are connected through carboxylate groups from glycine (1) and $\beta$-alanine (2), forming one-dimensional $\left\{\left[\mathrm{Gd}^{\mathrm{III}}{ }_{2}\right]^{6+}\right\}_{\text {n }}$ systems, the positive charges being counterbalanced by means of $\mathrm{ClO}_{4}{ }^{-}$anions. $\mathrm{H}_{2} \mathrm{O}$ solvent molecules are also present in their crystal structure (Figure 1). 
Table 1. Summary of the crystal data and structure refinement parameters for $\mathbf{1}$ and $\mathbf{2}$.

\begin{tabular}{|c|c|c|}
\hline Compound & 1 & 2 \\
\hline $\mathrm{CIF}$ & 2149741 & 2149742 \\
\hline Formula & $\mathrm{C}_{12} \mathrm{H}_{48} \mathrm{Cl}_{6} \mathrm{~N}_{6} \mathrm{O}_{45} \mathrm{Gd}_{2}$ & $\mathrm{C}_{18} \mathrm{H}_{52} \mathrm{Cl}_{6} \mathrm{~N}_{6} \mathrm{O}_{41} \mathrm{Gd}_{2}$ \\
\hline $\mathrm{Fw} / \mathrm{g} \mathrm{mol}^{-1}$ & 1523.76 & 1535.85 \\
\hline Temperature/K & $120(2)$ & $120(2)$ \\
\hline Crystal system & Triclinic & Triclinic \\
\hline Space group & $\mathrm{P}_{\overline{1}}$ & $\mathrm{P}_{\overline{1}}$ \\
\hline$a / \AA$ & $11.401(1)$ & $9.172(1)$ \\
\hline$b / \AA$ & $13.986(1)$ & $12.733(1)$ \\
\hline$c / \AA$ & $15.506(1)$ & $21.558(1)$ \\
\hline$\alpha /^{\circ}$ & $96.47(1)$ & $76.39(1)$ \\
\hline$\beta /{ }^{\circ}$ & $102.59(1)$ & $81.26(1)$ \\
\hline$\gamma /{ }^{\circ}$ & $105.99(1)$ & $82.47(1)$ \\
\hline$V / \AA^{3}$ & $2280.1(2)$ & $2406.9(2)$ \\
\hline Z & 2 & 2 \\
\hline$D_{\mathrm{c}} / \mathrm{g} \mathrm{cm}^{-3}$ & 2.219 & 2.119 \\
\hline$\mu\left(\mathrm{Mo}-\mathrm{K}_{\alpha}\right) / \mathrm{mm}^{-1}$ & 3.370 & 3.187 \\
\hline$F(000)$ & 1504 & 1520 \\
\hline Goodness-of-fit on $F^{2}$ & 1.013 & 0.989 \\
\hline$R_{1}[I>2 \sigma(I)] /$ all data & $0.0160 / 0.0175$ & $0.0274 / 0.0302$ \\
\hline $\mathrm{w} R_{2}[I>2 \sigma(I)] /$ all data & $0.0417 / 0.0426$ & $0.0741 / 0.0760$ \\
\hline
\end{tabular}

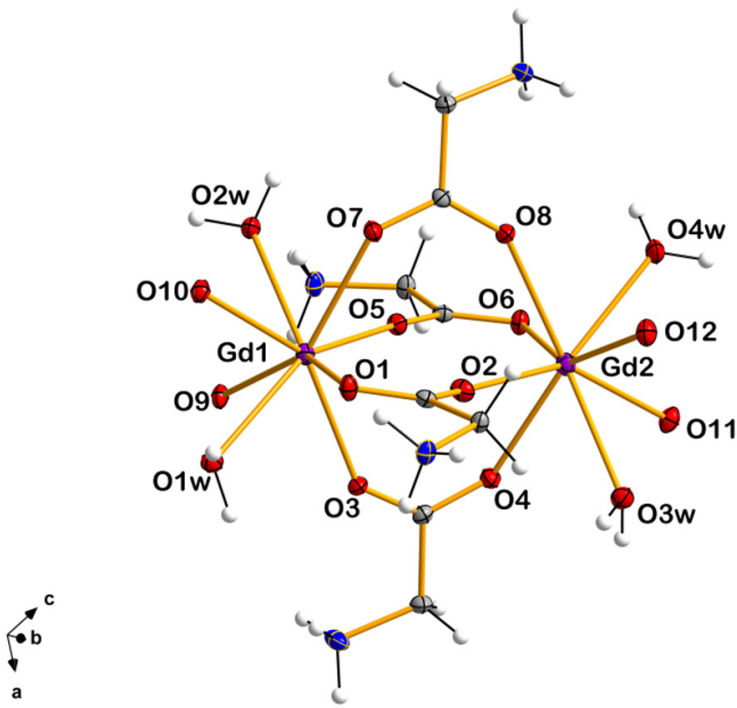

(a)

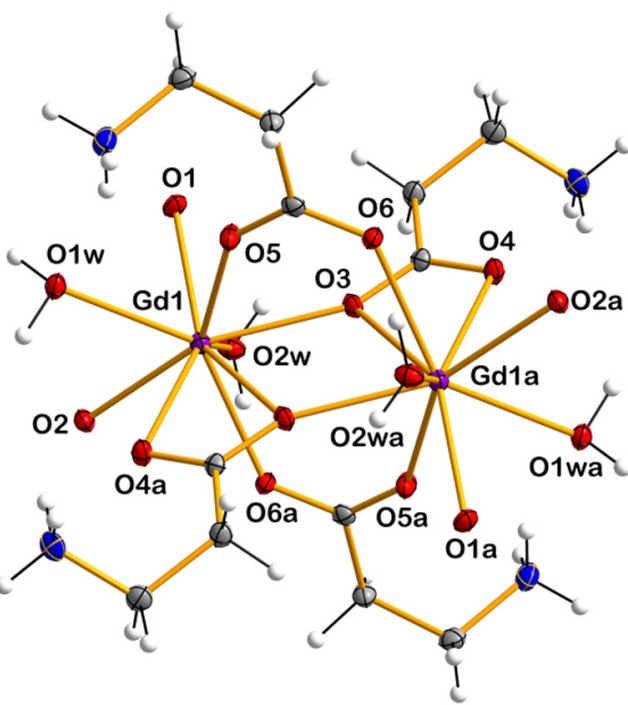

(b)

Figure 1. (a) Detail of the dinuclear $\left[\mathrm{Gd}_{2}(\mathrm{gly})_{6}\left(\mathrm{H}_{2} \mathrm{O}\right)_{4}\right]^{6+}$ unit in $\mathbf{1} ;(\mathbf{b})$ Detail of the dinuclear $\left[\mathrm{Gd}_{2}(\beta-\right.$ ala $\left.)_{6}\left(\mathrm{H}_{2} \mathrm{O}\right)_{4}\right]^{6+}$ unit in 2 . In both cases, perchlorate anions and non-coordinating water molecules were omitted for clarity. Thermal ellipsoids are depicted at the $50 \%$ probability level.

In complex 1, two Gd ${ }^{\mathrm{III}}$ ions of the dinuclear $\left[\mathrm{Gd}_{2}(\mathrm{gly})_{6}\left(\mathrm{H}_{2} \mathrm{O}\right)_{4}\right]^{6+}$ unit are linked between them through four bridging carboxylate groups of four glycinate ligands (gly). These two Gd ${ }^{\mathrm{III}}$ ions are separated by a distance of 4.223(1) A. Another two glycinate ligands connect these two $\mathrm{Gd}^{\mathrm{III}}$ ions to adjacent dinuclear units with separations of 5.229

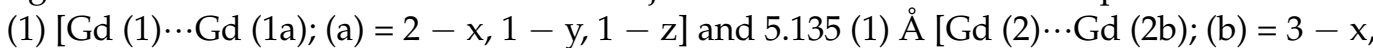
$2-\mathrm{y}, 2-\mathrm{z}]$, thus generating a $1 \mathrm{D}\left\{\left[\mathrm{Gd}^{\mathrm{III}}{ }_{2}\right]^{6+}\right\}_{\mathrm{n}}$ chain (Figure 2). Each $\mathrm{Gd}^{\mathrm{III}}$ ion of the dinuclear $\left[\mathrm{Gd}_{2}(\mathrm{gly})_{6}\left(\mathrm{H}_{2} \mathrm{O}\right)_{4}\right]^{6+}$ unit is eight-coordinate and bonded to six oxygen atoms from six glycinate ligands and two oxygen atoms of two water molecules (Figure 1). 


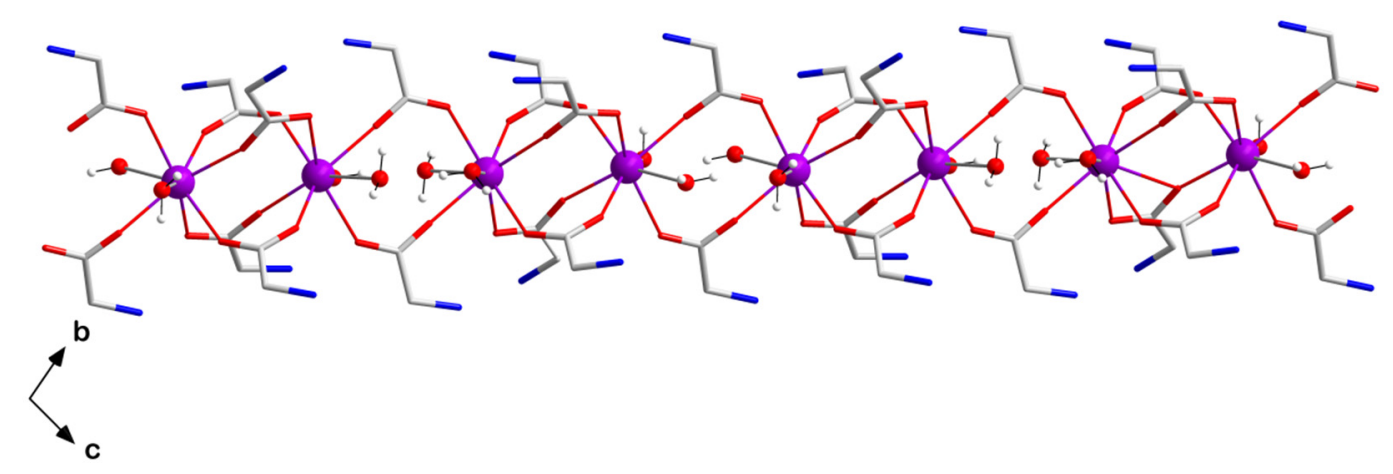

Figure 2. View of the one-dimensional motif of the homometallic $\left\{\left[\mathrm{Gd}_{2}(\mathrm{gly})_{6}\left(\mathrm{H}_{2} \mathrm{O}\right)_{4}\right]\left(\mathrm{ClO}_{4}\right)_{6} \cdot 5 \mathrm{H}_{2} \mathrm{O}\right\}_{\mathrm{n}}$ chain in 1. Perchlorate anions and non-coordinating water molecules were omitted for clarity. Colour code: violet, Gd; red, O; blue, N; grey, C; white, $\mathrm{H}$.

The Gd-O bond lengths exhibit an average value of 2.419 (1) $\AA$, which is somewhat shorter than that of the Gd-Ow bond lengths [2.506 (1) $\AA$ ] [24]. The glycinate ligands are present in their zwitterionic form with $\mathrm{C}-\mathrm{C}, \mathrm{C}-\mathrm{N}$, and $\mathrm{C}-\mathrm{O}$ bond lengths, which are in agreement with those found in the literature for similar lanthanide-based complexes $[25,26]$.

In the packing of $\mathbf{1}$, the cationic $\left\{\left[\mathrm{Gd}^{\mathrm{III}}{ }_{2}\right]^{6+}\right\}_{\mathrm{n}}$ chains are intercalated by $\mathrm{ClO}_{4}{ }^{-}$anions. The shortest interchain Gd...Gd distance is approximately 11.0(1) $\AA$. The dinuclear $\left[\mathrm{Gd}_{2}(\mathrm{gly})_{6}\left(\mathrm{H}_{2} \mathrm{O}\right)_{4}\right]^{6+}$ units in the chains of $\mathbf{1}$ are connected through H-bonding interactions, which involve coordinated water molecules [O $(1 w) \cdots \mathrm{O}(2 w a)$ and $\mathrm{O}(3 \mathrm{w}) \cdots \mathrm{O}(4 \mathrm{wb})$ distances of 2.844 (1) and 2.780 (1) $\AA$, respectively]. Further H-bonding interactions generated by protonated $-\mathrm{NH}_{2}$ groups of the glycinate ligands and $\mathrm{ClO}_{4}{ }^{-}$anions link the $\left\{\left[\mathrm{Gd}^{\mathrm{III}}{ }_{2}\right]^{6+}\right\}_{n}$ chains in the structure of $\mathbf{1}$, as previously reported in the study of other SMMs structures [27-29].

In complex 2, two $\mathrm{Gd}^{\mathrm{III}}$ ions are connected between them through four bridging carboxylate groups from four $\beta$-alanine $\left(\beta\right.$-ala) ligands to form the dinuclear $\left[\mathrm{Gd}_{2}(\beta\right.$ ala $\left.)_{6}\left(\mathrm{H}_{2} \mathrm{O}\right)_{4}\right]^{6+}$ unit. The two $\mathrm{Gd}^{\mathrm{III}}$ ions are distanced from each other by an average separation of ca. 4.008 (1) A (Figure 1), (the symmetry codes for the Gd (1)...Gd (1a) and Gd (2) $\cdots G d(2 b)$ distances being $(a)=-x, 1-y,-z$ and $(b)=1-x,-y, 1-z$, respectively). Additional $\beta$-ala ligands link adjacent dinuclear units with separations of 5.196 (1) [Gd (1) $\cdots \mathrm{Gd}(1 \mathrm{c}) ;(\mathrm{c})=1-\mathrm{x}, 1-\mathrm{y},-\mathrm{z}$ ] and 5.203 (1) $\AA$ [Gd (2) $\cdots \mathrm{Gd}(2 \mathrm{~d}) ;(\mathrm{d})=2-\mathrm{x},-\mathrm{y}, 1-\mathrm{z}$ ], generating a cationic $1 \mathrm{D}$ coordination polymer that grows along the crystallographic a-axis (Figure 3).

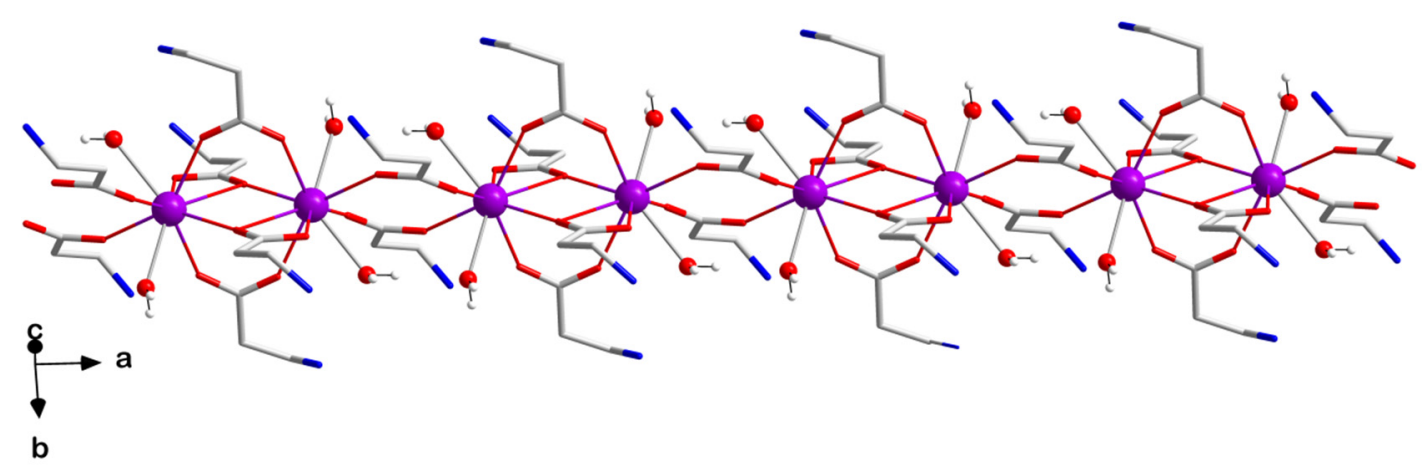

Figure 3. View of the one-dimensional motif of the homometallic $\left\{\left[\mathrm{Gd}_{2}(\beta-\right.\right.$ ala $\left.\left.\left.)_{6}\left(\mathrm{H}_{2} \mathrm{O}\right)_{4}\right]\left(\mathrm{ClO}_{4}\right)_{6} \cdot \mathrm{H}_{2} \mathrm{O}\right)\right\}_{n}$ chain in 2. Perchlorate anions and non-coordinating water molecules were omitted for clarity. Colour code: violet, Gd; red, O; blue, N; grey, C; white, $\mathrm{H}$.

Each $\mathrm{Gd}^{\mathrm{III}}$ ion in $\mathbf{2}$ is nine-coordinate and bonded to seven oxygen atoms from six carboxylate groups of $\beta$-ala ligands and two oxygen atoms of two water molecules (Figure 1). The average value of the Gd-O bond lengths [2.388 (1) $\AA$ ] is shorter than that of the Gd-Ow 
bond lengths [2.522 (1) $\AA$ ]. The $\beta$-ala ligands are coordinated in 2 as zwitterionic molecules and the values of the $\mathrm{C}-\mathrm{C}, \mathrm{C}-\mathrm{N}$, and $\mathrm{C}-\mathrm{O}$ bond lengths agree with those found in the literature for similar complexes based on other lanthanide (III) ions [26,30].

In the packing of 2, the cationic $\left\{\left[\mathrm{Gd}^{\mathrm{III}}{ }_{2}\right]^{6+}\right\}_{\mathrm{n}}$ chains and $\mathrm{ClO}_{4}{ }^{-}$anions are arranged in an alternate way. They are linked through intermolecular $\mathrm{H}$-bonding interactions involving non-coordinated water molecules and protonated $-\mathrm{NH}_{2}$ groups of $\beta$-ala ligands. The

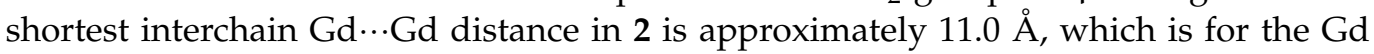
(2) $\cdots \mathrm{Gd}$ (1c) separation. The supramolecular structure of $\mathbf{2}$ is generated through additional H-bonding interactions.

\subsection{Analysis of the Polyhedral Structures}

The coordination environment and geometry of the Gd ${ }^{\mathrm{III}}$ ions in $\mathbf{1}$ and $\mathbf{2}$ were further analyzed through the SHAPE program [31-33]. In 1, the two Gd ${ }^{\mathrm{III}}$ ions show a coordination number equal to eight (Figure 1). The lower computed value for Gd (1) was 0.732, which was associated with a bicapped trigonal prism (BCTPR) geometry (Table 2). For Gd (2), however, a value of 0.915 was assigned to a square antiprism (SAPR) geometry (Figure 4 and Table 2). These features would suggest different geometries for the metal centers $\mathrm{Gd}$ (1) and Gd (2) in compound 1 (Figure 4).

Table 2. Selected values for possible geometries with coordination number $(\mathrm{CN})$ equal to 8 obtained through the SHAPE program and from structural parameters of complex $\mathbf{1}^{\mathrm{a}}$.

\begin{tabular}{cccccccccc}
\hline Metal Ion & HBPY & CU & SAPR & TDD & JGBF & JETBPY & BTPR & JSD & TT \\
\hline Gd(1) & 17.116 & 11.317 & 1.254 & 1.763 & 13.137 & 27.406 & 0.732 & 3.440 & 11.813 \\
Gd(2) & 13.944 & 9.336 & 0.915 & 2.077 & 12.464 & 28.179 & 1.167 & 3.889 & 9.984 \\
\hline
\end{tabular}

${ }^{a}$ HBPY: Hexagonal bipyramid $\left(\mathrm{D}_{6 \mathrm{~h}}\right)$; CU: Cube $(\mathrm{Oh})$; SAPR: Square antiprism $\left(\mathrm{D}_{4 \mathrm{~d}}\right)$; TDD: Triangular dodecahedron $\left(D_{2 \mathrm{~d}}\right)$; JGBF: Johnson gyrobifastigum $\left(\mathrm{D}_{2 \mathrm{~d}}\right)$; JETBPY: Johnson elongated triangular bipyramid $\left(\mathrm{D}_{3 \mathrm{~h}}\right)$; BTPR: Biaugmented trigonal prism $\left(\mathrm{C}_{2 \mathrm{v}}\right)$; JSD: Snub diphenoid $\left(\mathrm{D}_{2 \mathrm{~d}}\right)$; TT: Triakis tetrahedron $(\mathrm{Td})$.
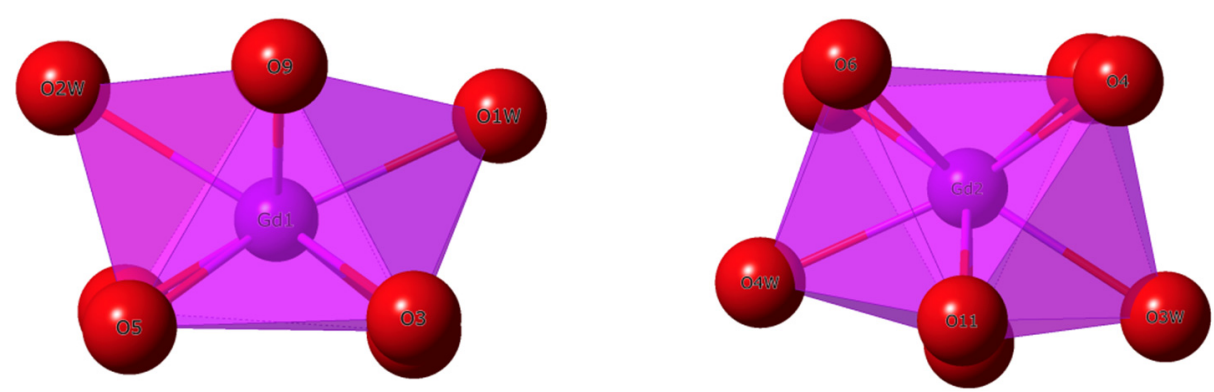

Figure 4. Polyhedral view of the coordination sphere around the gadolinium (III) ions of the dinuclear $\left[\mathrm{Gd}_{2}^{\mathrm{III}}\right]^{6+}$ unit in complex 1 [Gd (1), (left); Gd (2) (right)].

Unlike 1, the two $\mathrm{Gd}^{\mathrm{III}}$ ions of the dinuclear $\left[\mathrm{Gd}^{\mathrm{III}}{ }_{2}\right]^{6+}$ unit in compound 2 exhibit a coordination number equal to nine (Figure 1). The lower SHAPE values computed for these two Gd ${ }^{\mathrm{III}}$ ions were 1.117 and 1.208 for Gd (1) and Gd (2), respectively (Table 3). These calculated values were assigned to a capped square antiprism (CSAPR) geometry (Figure 5), hence indicating the same geometry for the $\mathrm{Gd}^{\mathrm{III}}$ ions in the dinuclear $\left[\mathrm{Gd}^{\mathrm{III}}{ }_{2}\right]^{6+}$ unit of $\mathbf{2}$.

Table 3. Selected values for possible geometries with coordination number $(\mathrm{CN})$ equal to 9 obtained through the SHAPE program and from structural parameters of complex $2^{\text {a }}$.

\begin{tabular}{cccccccccc}
\hline Metal Ion & HPY & JTC & JCCU & CSAPR & JTCTPR & TCTPR & JTDIC & HH & MFF \\
\hline Gd(1) & 19.213 & 15.400 & 10.340 & 1.117 & 2.255 & 1.543 & 12.866 & 10.100 & 1.368 \\
Gd(2) & 18.545 & 14.843 & 10.477 & 1.208 & 2.134 & 1.561 & 13.375 & 9.502 & 1.489 \\
\hline
\end{tabular}

${ }^{a}$ HPY: Heptagonal bipyramid $\left(D_{7 h}\right)$; JTC: Johnson triangular cupola $\left(C_{3 v}\right) ;$ JCCU: Capped cube $\left(C_{4 v}\right)$; CSAPR: Spherical capped square antiprism $\left(\mathrm{C}_{4 \mathrm{v}}\right)$; JTCTPR: Tricapped trigonal prism $\left(\mathrm{D}_{3 \mathrm{~h}}\right)$; TCTPR: Spherical tricapped trigonal prism $\left(\mathrm{D}_{3 \mathrm{~h}}\right)$; JTDIC: Tridiminished icosahedron $\left(\mathrm{C}_{3 \mathrm{v}}\right)$; HH: Hula-hoop $\left(\mathrm{C}_{2 \mathrm{v}}\right)$; MFF: Muffin $(\mathrm{Cs})$. 

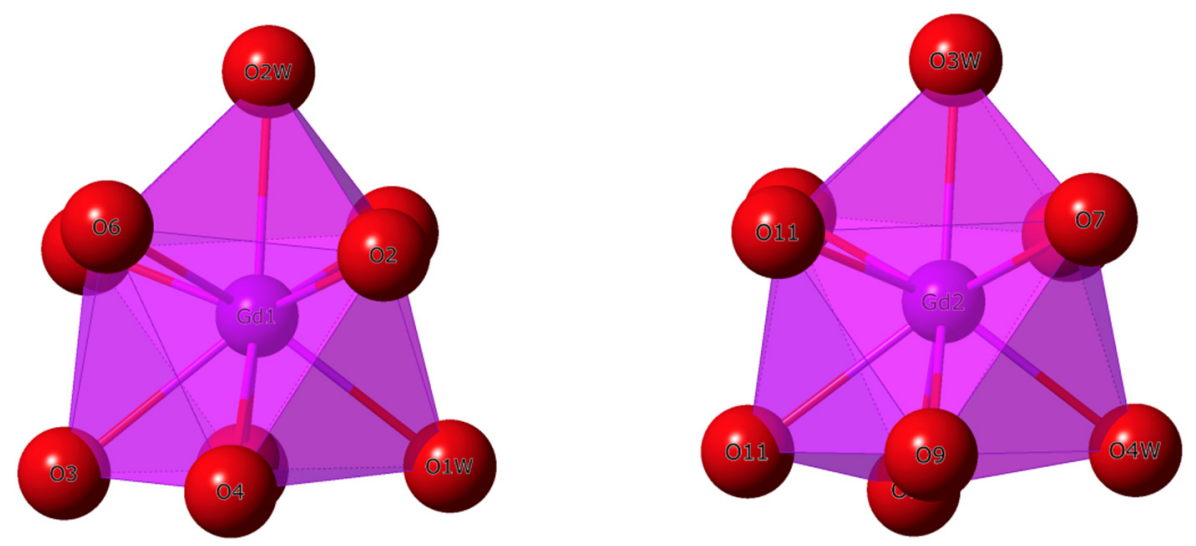

Figure 5. Polyhedral view of the coordination sphere around the gadolinium (III) ions of the dinuclear $\left[\mathrm{Gd}_{2}^{\mathrm{III}}{ }_{2}\right]^{6+}$ unit in complex 2 [Gd (1), (left); Gd (2) (right)].

As shown in Tables 2 and 3, these computed values for $\mathbf{1}$ allow us to assign the $\mathrm{C}_{2 \mathrm{v}}$ and $\mathrm{D}_{4 \mathrm{~d}}$ symmetries to the Gd (1) and Gd (2) ions, respectively, whereas both Gd ${ }^{\mathrm{III}}$ ions (Gd (1) and $\mathrm{Gd}(2)$ ) exhibit $\mathrm{C}_{4 \mathrm{v}}$ symmetry in 2 . In any case, they would be approximate symmetries.

\subsection{Magnetic Properties}

Dc magnetic susceptibility measurements were carried out on microcrystalline samples of 1 and 2 in the 2-300 K temperature range and under an external magnetic field of $0.5 \mathrm{~T}$. In order to keep the samples both immobilized and well isolated from the moisture of the air at all moments, the organic compound eicosene was used. The $\chi_{M} T$ versus $T$ plots ( $\chi_{\mathrm{M}}$ being the molar magnetic susceptibility per two $\mathrm{Gd}^{\mathrm{III}}$ ions) for compounds 1 and 2 are given in Figure 6. At room temperature, the $\chi_{M} T$ values are ca. 15.7 (1) and ca. $15.9 \mathrm{~cm}^{3} \mathrm{~mol}^{-1} \mathrm{~K}(2)$, which are very close to that expected for two magnetically uncoupled $\mathrm{Gd}^{\mathrm{III}}$ ions $\left(4 \mathrm{f}^{7}\right.$ ion with $g_{\mathrm{Gd}}=2.0, \mathrm{~S}_{\mathrm{Gd}}=7 / 2$ and $\left.\mathrm{L}_{\mathrm{Gd}}=0\right)$ [34]. Upon cooling, the $\chi_{\mathrm{M}} T$ values approximately follow the Curie law with decreasing temperature to ca. $20 \mathrm{~K}$, before they decrease reaching minimum values of approximately $13.4(\mathbf{1})$ and $14.0 \mathrm{~cm}^{3} \mathrm{~mol}^{-1} \mathrm{~K}(2)$ at $2 \mathrm{~K}$. The decrease in the $\chi_{M} T$ value observed for both compounds would likely be assignable to antiferromagnetic interactions and/or small zero-field splitting (ZFS) effects [20,21].

The field dependence of the molar magnetization $(M)$ plots for $\mathbf{1}$ and $\mathbf{2}$ are given in the respective insets of Figure 6 . The $M$ values display a continuous increase with the applied magnetic field at $2 \mathrm{~K}$. The higher $M$ value is ca. $14.0 \mu_{\mathrm{B}}$ for both compounds, which is in agreement with those of similar $\mathrm{Gd}^{\mathrm{III}}$ compounds containing dinuclear units $[35,36]$.
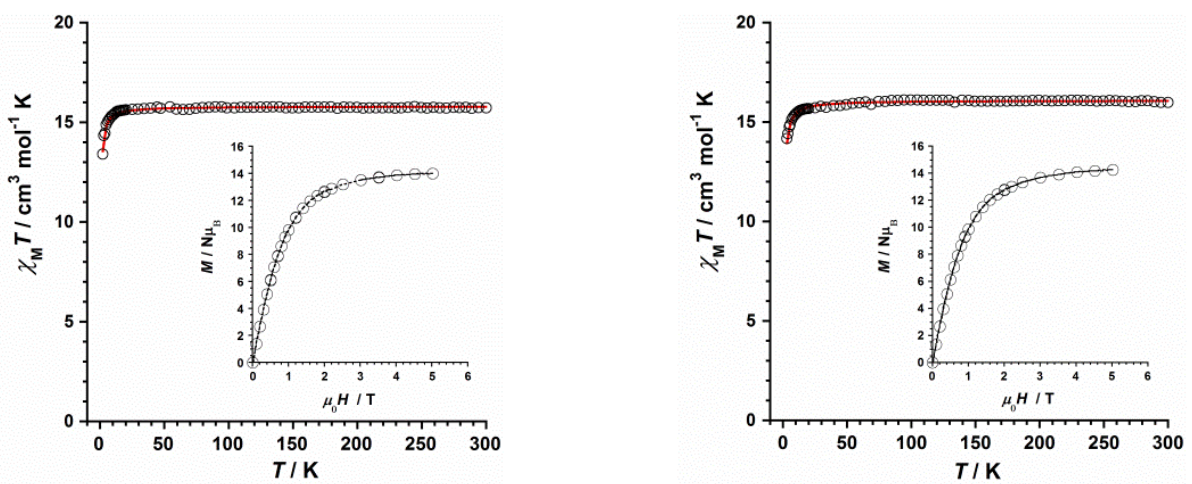

Figure 6. Thermal variation of the $\chi_{M}{ }^{T}$ product for complexes 1 (left) and 2 (right). The solid red line represents the theoretical fit of the experimental data and the inset shows the $\mathrm{M}$ versus $\mathrm{H}$ plot at $2.0 \mathrm{~K}$.

Taking into account the crystal structures described for $\mathbf{1}$ and 2, which are made up of linked dinuclear $\mathrm{Gd}^{\mathrm{III}}$ units, we considered them as magnetically isolated dinuclear $\mathrm{Gd}^{\mathrm{III}}$ 
systems. Thus, we performed the treatment of the experimental data of the $\chi_{M} T$ versus $T$ plots through the isotropic Hamiltonian of Equation (1):

$$
\hat{H}=-J \hat{S}_{1} \cdot \hat{S}_{2}+\mu_{\mathrm{B}} g H \hat{S}
$$

The best least-squares fit gave the parameters $J=-0.042(1) \mathrm{cm}^{-1}$ and $g=2.003(1)$ with $R=4.7 \times 10^{-5}$ for $\mathbf{1}$, and $J=-0.030$ (3) $\mathrm{cm}^{-1}$ and $g=2.002(1)$ with $R=5.2 \times 10^{-5}$ for $2\left\{R\right.$ being the agreement factor defined as $\left.\Sigma_{\mathrm{i}}\left[\left(\chi_{\mathrm{M}} T\right)_{\mathrm{i}}{ }^{\text {obs }}-\left(\chi_{\mathrm{M}} T\right)_{\mathrm{i}}{ }^{\text {calcd }}\right]^{2} /\left[\left(\chi_{\mathrm{M}} T\right)_{\mathrm{i}}{ }^{\text {obs }}\right]^{2}\right\}$. As shown in Figure 6, the calculated curves (solid red lines) reproduce the experimental magnetic data in the whole temperature range quite well. The sign and magnitude of the $J$ values indicate the presence of weak antiferromagnetic exchanges between the Gd $\mathrm{d}^{\mathrm{II}}$ ions connected through carboxylate bridges of the $\alpha$-glycine and $\beta$-alanine amino acids in 1 and 2, respectively. As far as we know, these $J$ values are the first ones reported for Gd $\mathrm{d}^{\mathrm{III}}$ complexes based on these two amino acids. Nevertheless, they are in agreement with those previously reported for $\mathrm{Gd}^{\mathrm{III}}$ systems linked through similar carboxylate bridges [36].

Ac magnetic susceptibility measurements were performed on $\mathbf{1}$ and $\mathbf{2}$ in the temperature range of $2-25 \mathrm{~K}$ and in a $5.0 \mathrm{G}$ ac field oscillating at different frequencies. No out-of-phase ac signals $\left(\chi^{\prime \prime} \mathrm{M}\right)$ were observed at $\mathrm{H}_{\mathrm{dc}}=0 \mathrm{G}$, which may be caused by a very fast Quantum Tunnelling of Magnetization (QTM) in $\mathbf{1}$ and 2. Nevertheless, out-of-phase ac signals were observed in both compounds when an external dc magnetic field (the optimal field being $\mathrm{H}_{\mathrm{dc}}=2500 \mathrm{G}$ ) was applied. This applied dc magnetic field suppresses QTM and breaks the Kramer's doublet, leading to the observed slow relaxation [17,20,21]. In this way, both compounds show field-induced slow relaxation of magnetization, which is indicative of single-molecule magnet (SMM) behavior [4,7]. This magnetic relaxation observed for 1 and 2 was studied through both in-phase $\left(\chi_{M^{\prime}}\right)$ and out-of-phase $\left(\chi_{M}{ }^{\prime \prime}\right)$ ac susceptibilities versus frequency $(v / \mathrm{Hz})$ plots, which are given in Figures 7 and 8 , respectively. The experimental data of the maxima in $\mathbf{2}$ display higher intensity than those of $\mathbf{1}$, even though similar relaxation dynamics could be a priori expected for both compounds.
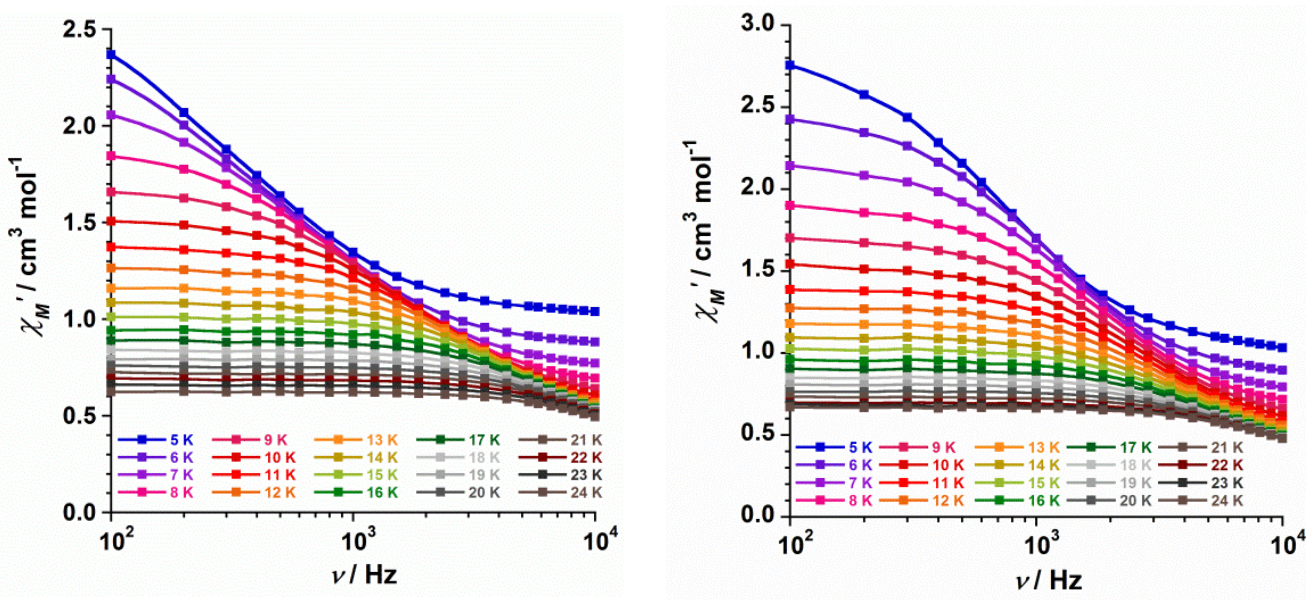

Figure 7. Frequency dependence of the in-phase ac susceptibility signals under a dc field of $2500 \mathrm{G}$ for 1 (left) and 2 (right).

The insets in Figure 8 show the $\ln (\tau)$ versus $1 /$ T curves for 1 and 2 . In both compounds, the experimental data draw a straight line along the ranges of ca. 0.03-0.15 (1) and ca. 0.04-0.07 $\mathrm{K}^{-1}(2)$ of the high-temperature region of 1 and 2, which connect with other straight-line behavior in the ranges of ca. $0.20-0.47(\mathbf{1})$ and ca. $0.09-0.44 \mathrm{~K}^{-1}$ (2) of the low-temperature region. In order to fit the experimental data of the $\ln (\tau)$ versus $1 / \mathrm{T}$ plots, several relaxation mechanisms were considered for both compounds [7,9]. Nevertheless, the whole $\ln (\tau)$ versus $1 / \mathrm{T}$ curves were reasonably fitted through two mechanisms for the 
relaxation of magnetization, namely, Orbach $\left[\tau_{\mathrm{o}}{ }^{-1} \exp \left(-\mathrm{U}_{\mathrm{eff}} / \mathrm{k}_{\mathrm{B}} T\right)\right]$ and Raman $\left[C T^{\mathrm{n}}\right]$, according to Equation (2):

$$
\tau^{-1}=\tau_{\mathrm{o}}{ }^{-1} \exp \left(-\mathrm{U}_{\mathrm{eff}} / \mathrm{k}_{\mathrm{B}} T\right)+C T^{n}
$$

The least-squares fit of the experimental data of $\mathbf{1}$ and $\mathbf{2}$ through Equation (2) leads to the following set of parameters: $U_{\text {eff }}=26.3(2) \mathrm{cm}^{-1}, \tau_{\mathrm{o}}=3.1(2) \times 10^{-6} \mathrm{~s}, \mathrm{C}=168(5) \mathrm{s}^{-1} \mathrm{~K}^{-\mathrm{n}}$ and $n=1.5(2)$ for 1 , and $\mathrm{U}_{\text {eff }}=7.8(2) \mathrm{cm}^{-1}, \tau_{\mathrm{o}}=2.6(1) \times 10^{-5} \mathrm{~s}, C=2.6(2) \mathrm{s}^{-1} \mathrm{~K}^{-\mathrm{n}}$, and $n=3.1$ (2) for 2. Although these values are the first ones reported for one-dimensional homometallic $\mathrm{Gd}^{\mathrm{III}}$ complexes based on these amino acids, they are close to those previously reported for similar $\mathrm{Gd}^{\mathrm{III}}$ complexes [12,13]. The values of the effective energy barrier $\left(\mathrm{U}_{\text {eff }}\right)$ obtained for $\mathbf{1}$ and $\mathbf{2}$ are lower than those reported for the derivatives complexes containing Dy ${ }^{\mathrm{III}}$ ion [26]. Nevertheless, the $\mathrm{U}_{\text {eff }}$ values reported for $\mathbf{1}$ and $\mathbf{2}$ should be carefully considered as they could not correspond to any excited $\mathrm{Gd}^{\mathrm{III}}$ states and therefore would not be real effective energy barrier values [13,21].
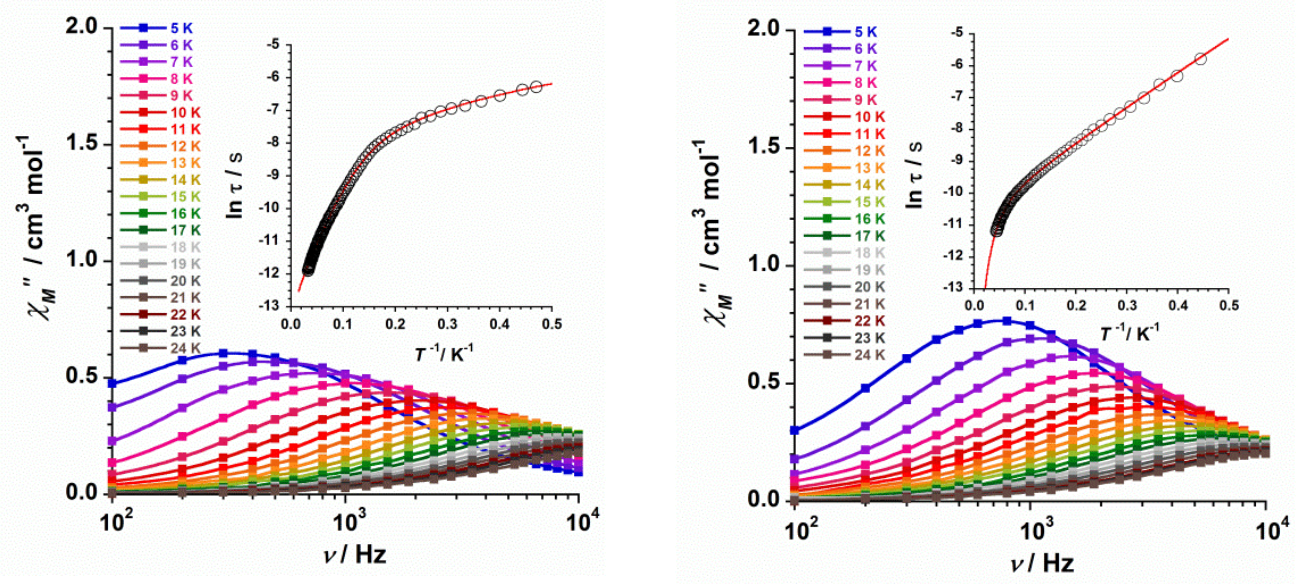

Figure 8. Frequency dependence of the out-of-phase ac susceptibility signals under a dc field of $2500 \mathrm{G}$ for 1 (left) and 2 (right). The inset shows the $\ln (\tau)$ versus $1 / \mathrm{T}$ plot with the fit considering the contribution of two mechanisms (Orbach + Raman).

The local symmetries displayed in the dinuclear $\mathrm{Gd}^{\mathrm{III}}$ units are $\mathrm{C}_{2 \mathrm{v}}$ and $\mathrm{D}_{4 \mathrm{~d}}$ in $\mathbf{1}$ and $\mathrm{C}_{4 \mathrm{v}}$ in 2. According to previous lanthanide (III) complexes studies, a priori, the local symmetry $\mathrm{D}_{4 \mathrm{~d}}$ found in $\mathbf{1}$ would lead to better SMM properties [5-7], as observed for its $\mathrm{U}_{\text {eff }}$ value when compared with that of 2 , but this fact relies at last on the relative orientation of the magnetic anisotropy axes of all the spin carriers [26].

The $\tau_{\mathrm{o}}$ values obtained for $\mathbf{1}$ and $\mathbf{2}$, being approximately $10^{-6}-10^{-5} \mathrm{~s}$, are in agreement with those previously reported for single-ion and single-molecule magnets [13,17], which supports our consideration that the predominant magnetic behavior in both compounds would be that of dinuclear single-molecule magnets, rather than a single-chain magnet.

Finally, according to our results, the relaxation pathway for $\mathbf{1}$ and $\mathbf{2}$ should be a combination of different processes, namely, Orbach (at a higher temperature) and Raman (at a lower temperature), both of them involving two phonons. The reported $n$ value for 1 $(n \approx 2)$ would indicate the presence at least of a phonon bottleneck effect, whereas the $n$ value for $3(n \approx 3)$ would indicate the contribution of a Raman mechanism, as previously reported [37]. These $n$ values suggest that only a direct process would not be operative in the relaxation dynamics of $\mathbf{1}$ and $\mathbf{2}$. In any case, further detailed magnetic and theoretical studies performed on different $\mathrm{Gd}^{\mathrm{III}}$ complexes will be necessary to correctly understand the relaxation dynamics of $\mathrm{Gd}^{\mathrm{III}} \mathrm{SMMs}$. 


\section{Experimental Section}

\subsection{Preparation of the Complexes \\ 3.1.1. Synthesis of $\left\{\left[\mathrm{Gd}_{2}(\mathrm{gly})_{6}\left(\mathrm{H}_{2} \mathrm{O}\right)_{4}\right]\left(\mathrm{ClO}_{4}\right)_{6} \cdot 5 \mathrm{H}_{2} \mathrm{O}\right\}_{\mathrm{n}}(1)$}

A solvothermal reaction of $\mathrm{Gd}_{2} \mathrm{O}_{3}(0.072 \mathrm{~g}, 0.20 \mathrm{mmol})$ and glycine $(0.030 \mathrm{~g}, 0.40 \mathrm{mmol})$ was performed in an aqueous suspension $(2 \mathrm{~mL})$ acidulated with perchloric acid $(1.0 \mathrm{~mL}$, $2 \mathrm{M})$ at $80{ }^{\circ} \mathrm{C}$ for $48 \mathrm{~h}$, followed by a cooling process at $4.5^{\circ} \mathrm{C} / \mathrm{h}$ to room temperature. Colourless parallelepipeds were obtained and were suitable for single-crystal X-ray diffraction studies. Yield: ca. $60 \%$. Anal. Calcd. for $\mathrm{C}_{12} \mathrm{H}_{48} \mathrm{~N}_{6} \mathrm{O}_{45} \mathrm{Cl}_{6} \mathrm{Gd}_{2}$ (1): $\mathrm{C}, 9.5 ; \mathrm{H}, 3.2 ; \mathrm{N}$, 5.5. Found: $\mathrm{C}, 9.9 ; \mathrm{H}, 3.0 ; \mathrm{N}$, 5.3. SEM-EDAX: a molar ratio of $1: 3$ for $\mathrm{Gd} / \mathrm{Cl}$ was found for 1 . IR (KBr pellet): peaks associated mainly to the glycine ligand and also to the perchlorate anion are observed at $3407(\mathrm{~s}), 3080(\mathrm{~m}), 3006(\mathrm{~m}), 2781(\mathrm{w}), 2708(\mathrm{w}), 1628(\mathrm{vs}), 1609(\mathrm{vs}), 1570(\mathrm{~m})$, 1499 (m), 1466 (m), 1413 (m), 1335 (m), 1144 (vs), 1109 (vs), 1088 (s), 905 (m), 626 (s), $536(\mathrm{w})$, $507(\mathrm{w}) \mathrm{cm}^{-1}$.

\subsubsection{Synthesis of $\left.\left\{\left[\mathrm{Gd}_{2}(\beta-\mathrm{ala})_{6}\left(\mathrm{H}_{2} \mathrm{O}\right)_{4}\right]\left(\mathrm{ClO}_{4}\right)_{6} \cdot \mathrm{H}_{2} \mathrm{O}\right)\right\}_{\mathrm{n}}(2)$}

A mixture of $\mathrm{Gd}_{2} \mathrm{O}_{3}(0.090 \mathrm{~g}, 0.25 \mathrm{mmol})$ and $\beta$-alanine $(0.022 \mathrm{~g}, 0.25 \mathrm{mmol})$ in an aqueous suspension $(5 \mathrm{~mL})$ acidulated with perchloric acid $(1.0 \mathrm{~mL}, 2 \mathrm{M})$ was stirred and heated at $60{ }^{\circ} \mathrm{C}$ for $1 \mathrm{~h}$. The resulting solution was left to evaporate at room temperature for 2 weeks. Colourless needles were obtained, which were suitable for single-crystal X-ray diffraction. Yield: ca. $55 \%$. Anal. Calcd for $\mathrm{C}_{18} \mathrm{H}_{52} \mathrm{~N}_{6} \mathrm{O}_{41} \mathrm{Cl}_{6} \mathrm{Gd}_{2}$ (2): $\mathrm{C}, 14.1 ; \mathrm{H}, 3.4 ; \mathrm{N}, 5.5$. Found: $\mathrm{C}, 14.0 ; \mathrm{H}, 3.3 ; \mathrm{N}, 5.6$. SEM-EDAX: a molar ratio of $1: 3$ for $\mathrm{Gd} / \mathrm{Cl}$ was found for 2 . IR (KBr pellet): peaks associated to $\beta$-alanine ligand and perchlorate anion are observed at 3396 (s), 1622 (s), 1578 (s), 1460 (s), 1406 (m), 1336 (m), $1312(\mathrm{w}), 1264(\mathrm{w}), 1144$ (vs), 1116 (vs), $1090(\mathrm{~s}), 958(\mathrm{~m}), 941(\mathrm{w}), 641(\mathrm{~m}), 627(\mathrm{~s}), 590(\mathrm{w}), 520(\mathrm{w}) \mathrm{cm}^{-1}$.

\subsection{X-ray Data Collection and Structure Refinement}

X-ray diffraction data collection on single crystals of dimensions $0.18 \times 0.11 \times 0.09$ (1) and $0.18 \times 0.09 \times 0.06 \mathrm{~mm}^{3}$ (2) were collected on a Bruker D8 Venture diffractometer with PHOTON II detector and by using monochromatised Mo- $\mathrm{K}_{\alpha}$ radiation $(\lambda=0.71073$ $\AA$ ). Crystal parameters and refinement results for $\mathbf{1}$ and $\mathbf{2}$ are summarized in Table 1 . The structures were solved by standard direct methods and subsequently completed by Fourier recycling using the SHELXTL [38] software packages and refined by the full-matrix least-squares refinements based on $\mathrm{F}^{2}$ with all observed reflections. The final graphical manipulations were performed with the DIAMOND [39] and CRYSTALMAKER [40] programs. CCDC 2,149,741 and 2,149,742 for 1 and 2, respectively.

\subsection{Physical Measurements}

Elemental analyses $(\mathrm{C}, \mathrm{H}, \mathrm{N})$ were performed in an Elemental Analyzer $\mathrm{CE}$ Instrument CHNS1100 and the molar ratio between heavier elements was found by means of a Philips XL-30 scanning electron microscope (SEM-EDAX), equipped with a system of X-ray microanalysis, in the Central Service for the Support to Experimental Research (SCSIE) at the University of Valencia. Infrared spectra (IR) of $\mathbf{1}$ and $\mathbf{2}$ were recorded with a PerkinElmer Spectrum 65 FT-IR spectrometer in the $4000-400 \mathrm{~cm}^{-1}$ range. Variable-temperature, solidstate (dc and ac) magnetic susceptibility data were collected on Quantum Design MPMS-XL SQUID and Physical Property Measurement System (PPMS) magnetometers. Experimental magnetic data were corrected for the diamagnetic contributions of both the sample holder and the eicosene. The diamagnetic contribution of the involved atoms was corrected by using Pascal's constants [41].

\section{Conclusions}

In summary, the synthesis, crystal structure and magnetic properties of two one-dimensional Gd $^{\text {III }}$ complexes based on the $\alpha$-glycine (gly) and $\beta$-alanine ( $\beta$-ala) amino acids, with the formula $\left\{\left[\mathrm{Gd}_{2}(\text { gly })_{6}\left(\mathrm{H}_{2} \mathrm{O}\right)_{4}\right]\left(\mathrm{ClO}_{4}\right)_{6} \cdot 5 \mathrm{H}_{2} \mathrm{O}\right\}_{\mathrm{n}}(\mathbf{1})$ and $\left\{\left[\mathrm{Gd}_{2}(\beta \text {-ala })_{6}\left(\mathrm{H}_{2} \mathrm{O}\right)_{4}\right]\left(\mathrm{ClO}_{4}\right)_{6} \cdot \mathrm{H}_{2} \mathrm{O}\right\}_{\mathrm{n}}$ (2), were reported. Their structures are described as cationic dinuclear $\left[\mathrm{Gd}_{2}^{\mathrm{III}}\right]^{6+}$ units which 
are connected through carboxylate groups from glycine (1) and $\beta$-alanine (2), forming one-dimensional $\left\{\left[\mathrm{Gd}^{\mathrm{III}}{ }_{2}\right]^{6+}\right\}_{\mathrm{n}}$ systems. Different symmetries of the $\mathrm{Gd}^{\mathrm{III}}$ ions, namely, $\mathrm{C}_{2 \mathrm{v}}$ and $\mathrm{D}_{4 \mathrm{~d}}$ in $\mathbf{1}$ and $\mathrm{C}_{4 \mathrm{v}}$ in $\mathbf{2}$, were found in the study of their coordination environment.

The investigation of the magnetic properties of $\mathbf{1}$ and $\mathbf{2}$ through dc magnetic susceptibility measurements reveals a similar magnetic behavior, with both compounds exhibiting weak antiferromagnetic exchange couplings between $\mathrm{Gd}^{\mathrm{III}}$ ions. In addition, ac magnetic susceptibility measurements show field-induced slow relaxation of magnetization for both 1 and 2, which indicates that the single-molecule magnet (SMM) phenomenon takes place in these novel one-dimensional $\mathrm{Gd}^{\text {III }}$ complexes.

Supplementary Materials: The following supporting information can be downloaded at: https: / / www.mdpi.com/article/10.3390/inorganics10030032/s1, CIF files 2149741 (1) and 2149742 (2).

Author Contributions: Conceptualization, J.M.-L.; funding acquisition, I.C., F.L. and J.M.-L.; methodology, M.O.-A., A.S.-P., N.M., I.C. and J.M.-L.; investigation, M.O.-A., A.S.-P., N.M., F.L. and J.M.-L.; formal analysis, M.O.-A., A.S.-P., N.M., I.C. and J.M.-L.; writing-original draft preparation, J.M.-L.; writing - review and editing, J.M.-L. All authors have read and agreed to the published version of the manuscript.

Funding: This research was funded by the Spanish Ministry of Science and Innovation (Grant numbers PID2019-109735GB-I00 and CEX2019-000919-M (Excellence Unit "María de Maeztu")) and also by the VLC-BIOMED Program of the University of Valencia (Grant number PI-2020-19DIGABIO).

Institutional Review Board Statement: Not applicable.

Informed Consent Statement: Not applicable.

Data Availability Statement: The raw data that support the findings of this study are available from the corresponding author upon reasonable request.

Acknowledgments: The authors M.O.-A. and A.S.-P. thank the Spanish "FPI fellowships" and "FPU fellowships" programs, respectively.

Conflicts of Interest: The authors declare no conflict of interest.

\section{References}

1. Ishikawa, N.; Sugita, M.; Ishikawa, T.; Koshihara, S.Y.; Kaizu, Y. Lanthanide double-decker complexes functioning as magnets at the single-molecular level. J. Am. Chem. Soc. 2003, 125, 8694-8695. [CrossRef]

2. Ishikawa, N.; Sugita, M.; Ishikawa, T.; Koshihara, S.Y.; Kaizu, Y. Mononuclear Lanthanide Complexes with a Long Magnetization Relaxation Time at High Temperatures: A New Category of Magnets at the Single-Molecular Level. J. Phys. Chem. B 2004, 108, 11265-11271. [CrossRef]

3. Habib, F.; Murugesu, M. Lessons learned from dinuclear lanthanide nano-magnets. Chem. Soc. Rev. 2013, 42, 3278-3288. [CrossRef]

4. Ferrando-Soria, J.; Vallejo, J.; Castellano, M.; Martínez-Lillo, J.; Pardo, E.; Cano, J.; Castro, I.; Lloret, F.; Ruiz-García, R.; Julve, M. Molecular magnetism, quo vadis? A historical perspective from a coordination chemist viewpoint. Coord. Chem. Rev. 2017, 339, 17-103. [CrossRef]

5. Liu, J.-L.; Chen, Y.-C.; Tong, M.-L. Symmetry strategies for high performance lanthanide-based single-molecule magnets. Chem. Soc. Rev. 2018, 47, 2431-2453. [CrossRef] [PubMed]

6. Dey, A.; Kalita, P.; Chandrasekhar, V. Lanthanide(III)-Based Single-Ion Magnets. ACS Omega 2018, 3, 9462-9475. [CrossRef] [PubMed]

7. Zabala-Lekuona, A.; Seco, J.M.; Colacio, E. Single-Molecule Magnets: From Mn12-ac to dysprosium metallocenes, a travel in time. Coord. Chem. Rev. 2021, 441, 213984. [CrossRef]

8. Gebrezgiabher, M.; Bayeh, Y.; Gebretsadik, T.; Gebreslassie, G.; Elemo, F.; Thomas, M.; Linert, W. Lanthanide-Based SingleMolecule Magnets Derived from Schiff Base Ligands of Salicylaldehyde Derivatives. Inorganics 2020, 8, 66. [CrossRef]

9. McAdams, S.G.; Ariciu, A.-M.; Kostopoulos, A.K.; Walsh, J.P.S.; Tuna, F. Molecular single-ion magnets based on lanthanides and actinides: Design considerations and new advances in the context of quantum technologies. Coord. Chem. Rev. 2017, 346, 216-239. [CrossRef]

10. Karotsis, G.; Evangelisti, M.; Dalgarno, S.J.; Brechin, E.K. A Calix[4 ]arene 3d/4f Magnetic Cooler. Angew. Chem. Int. Ed. 2009, 48, 9928-9931. [CrossRef] 
11. Ghosh, T.K.; Maity, S.; Mayans, J.; Ghosh, A. Family of Isomeric Cu ${ }^{\mathrm{II}}-\mathrm{Ln}^{\mathrm{III}}(\mathrm{Ln}=\mathrm{Gd}, \mathrm{Tb}$, and Dy) Complexes Presenting Field-

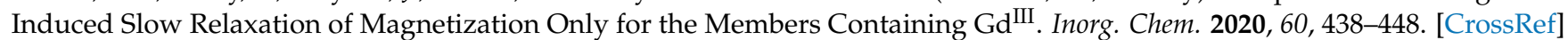
[PubMed]

12. Borah, A.; Murugavel, R. Magnetic relaxation in single-ion magnets formed by less-studied lanthanide ions $\mathrm{Ce}(\mathrm{III}), \mathrm{Nd}(\mathrm{III})$, Gd(III), Ho(III), Tm(II/III) and Yb(III). Coord. Chem. Rev. 2022, 453, 214288. [CrossRef]

13. Maciel, J.W.D.O.; Lemes, M.A.; Valdo, A.K.; Rabelo, R.; Martins, F.T.; Maia, L.J.Q.; Costa de Santana, R.; Lloret, F.; Julve, M.; Cangussu, D. Europium(III), Terbium(III), and Gadolinium(III) Oxamato-Based Coordination Polymers: Visible Luminescence and Slow Magnetic Relaxation. Inorg. Chem. 2021, 60, 6176-6190. [CrossRef] [PubMed]

14. Rodríguez-Barea, B.; Mayans, J.; Rabelo, R.; Sanchis-Perucho, A.; Moliner, N.; Martínez-Lillo, J.; Julve, M.; Lloret, F.; Ruiz-García, R.; Cano, J. Holmium(III) Single-Ion Magnet for Cryomagnetic Refrigeration Based on an MRI Contrast Agent Derivative. Inorg. Chem. 2021, 60, 12719-12723. [CrossRef]

15. Orts-Arroyo, M.; Rabelo, R.; Carrasco-Berlanga, A.; Moliner, N.; Cano, J.; Julve, M.; Lloret, F.; De Munno, G.; Ruiz-García, R.; Mayans, J.; et al. Field-induced slow magnetic relaxation and magnetocaloric effects in an oxalato-bridged gadolinium(III)-based 2D MOF. Dalton Trans. 2021, 50, 3801-3805. [CrossRef]

16. Arauzo, A.; Lazarescu, A.; Shova, S.; Bartolomé, E.; Cases, R.; Luzón, J.; Bartolomé, J.; Turta, C. Structural and magnetic properties of some lanthanide ( $\mathrm{Ln}=\mathrm{Eu}(\mathrm{III}), \mathrm{Gd}(\mathrm{III})$ and $\mathrm{Nd}(\mathrm{III})$ ) cyanoacetate polymers: Field-induced slow magnetic relaxation in the $\mathrm{Gd}$ and Nd substitutions. Dalton Trans. 2014, 43, 12342-12356. [CrossRef]

17. Izuogu, D.C.; Yoshida, T.; Zhang, H.; Cosquer, G.; Katoh, K.; Ogata, S.; Hasegawa, M.; Nojiri, H.; Damjanović, M.; Wernsdorfer, W.; et al. Slow Magnetic Relaxation in a Palladium-Gadolinium Complex Induced by Electron Density Donation from the Palladium Ion. Chem. Eur. J. 2018, 24, 9285-9294. [CrossRef]

18. Guo, F.-S.; Day, B.M.; Chen, Y.-C.; Tong, M.-L.; Mansikkamäki, A.; Layfield, R.A. Magnetic hysteresis up to 80 kelvin in a dysprosium metallocene single-molecule magnet. Science 2018, 362, 1400-1403. [CrossRef]

19. Ullah, A.; Cerdá, J.; Baldoví, J.J.; Varganov, S.A.; Aragó, J.; Gaita-Ariño, A. In Silico Molecular Engineering of DysprosoceniumBased Complexes to Decouple Spin Energy Levels from Molecular Vibrations. J. Phys. Chem. Lett. 2019, 10, 7678-7683. [CrossRef]

20. Chen, Y.-C.; Peng, Y.-Y.; Liu, J.-L.; Tong, M.-L. Field-induced slow magnetic relaxation in a mononuclear Gd(III) complex. Inorg. Chem. Commun. 2019, 107, 107449. [CrossRef]

21. Mayans, J.; Escuer, A. Correlating the axial Zero Field Splitting with the slow magnetic relaxation in Gd ${ }^{\mathrm{III}}$ SIMs. Chem. Commun. 2021, 57, 721-724. [CrossRef] [PubMed]

22. Lu, J.-L.; Liu, B.-P.; Tan, Z.-C.; Zhang, D.-S.; Li, L.; Chen, Y.-D.; Shi, Q. Synthesis, Crystal Structure and Themochemical Study of $\left[\mathrm{Gd}_{2}(\mathrm{Gly})_{6}\left(\mathrm{H}_{2} \mathrm{O}\right)_{4}\right]\left(\mathrm{ClO}_{4}\right)_{6}\left(\mathrm{H}_{2} \mathrm{O}\right)_{5}$. Acta Chim. Sin. Chin. Ed. 2007, 65, 2349-2355.

23. Liang, F.-P.; Ma, L.-F.; Huang, S.-W.; Huang, Y.-Q. Synthesis, Crystal Structure and Antibacterial Activity of $\beta$-Alanine Complexes with Nd, Gd, Er. Chin. J. Appl. Chem. 2004, 21, 58-62.

24. Orts-Arroyo, M.; Ten-Esteve, A.; Ginés-Cárdenas, S.; Castro, I.; Martí-Bonmatí, L.; Martínez-Lillo, J. A Gadolinium(III) Complex Based on the Thymine Nucleobase with Properties Suitable for Magnetic Resonance Imaging. Int. J. Mol. Sci. 2021, 22, 4586. [CrossRef]

25. Legendziewicz, J.; Huskowska, E.; Waśkowska, A.; Argay, G. Spectroscopy and crystal structure of neodymium coordination compound with glycine: $\mathrm{Nd}_{2}(\mathrm{Gly})_{6} \cdot\left(\mathrm{ClO}_{4}\right)_{6} \cdot 9 \mathrm{H}_{2} \mathrm{O}$. Inorg. Chim. Acta 1984, 92, 151-157. [CrossRef]

26. Orts-Arroyo, M.; Castro, I.; Lloret, F.; Martínez-Lillo, J. Field-induced slow relaxation of magnetisation in two one-dimensional homometallic dysprosium(III) complexes based on alpha- and beta-amino acids. Dalton Trans. 2020, 49, 9155-9163. [CrossRef]

27. Martínez-Lillo, J.; Dolan, N.; Brechin, E.K. A cationic and ferromagnetic hexametallic Mn(III) single-molecule magnet based on the salicylamidoxime ligand. Dalton Trans. 2013, 42, 12824-12827. [CrossRef]

28. Martínez-Lillo, J.; Dolan, N.; Brechin, E.K. A family of cationic oxime-based hexametallic manganese(III) single-molecule magnets. Dalton Trans. 2014, 43, 4408-4414. [CrossRef]

29. Rojas-Dotti, C.; Moliner, N.; Lloret, F.; Martínez-Lillo, J. Ferromagnetic Oxime-Based Manganese(III) Single-Molecule Magnets with Dimethylformamide and Pyridine as Terminal Ligands. Crystals 2019, 9, 23. [CrossRef]

30. Jianxue, L.; Ninghai, H.; Chunji, N.; Qingbo, M. The crystal structure of a samarium complex with $\beta$-alanine. J. Alloys Compd. 1992, 184, L1-L3. [CrossRef]

31. Llunell, M.; Casanova, D.; Cirera, J.; Alemany, P.; Alvarez, S. SHAPE 2.1; Universitat de Barcelona: Barcelona, Spain, 2013.

32. Alvarez, S.; Alemany, P.; Casanova, D.; Cirera, J.; Llunell, M.; Avnir, D. Shape maps and polyhedral interconversion paths in transition metal chemistry. Coord. Chem. Rev. 2005, 249, 1693-1708. [CrossRef]

33. Ruiz-Martínez, A.; Casanova, D.; Alvarez, S. Polyhedral Structures with an Odd Number of Vertices: Nine-Coordinate Metal Compounds. Chem. Eur. J. 2008, 14, 1291-1303. [CrossRef] [PubMed]

34. Martínez-Lillo, J.; Cañadillas-Delgado, L.; Cano, J.; Lloret, F.; Julve, M.; Faus, J. A heteropentanuclear oxalato-bridged [Re $\left.{ }^{\mathrm{IV}}{ }_{4} \mathrm{Gd}^{\mathrm{III}}\right]$ complex: Synthesis, crystal structure and magnetic properties. Chem. Commun. 2012, 48, 9242-9244. [CrossRef]

35. Roy, L.E.; Hughbanks, T. Magnetic Coupling in Dinuclear Gd Complexes. J. Am. Chem. Soc. 2006, 128, 568-575. [CrossRef] [PubMed]

36. Cañadillas-Delgado, L.; Fabelo, O.; Cano, J.; Ruiz-Pérez, C. Magnetic Interactions in Oxo-Carboxylate Bridged Gadolinium(III) Complexes Synthesis, Crystal Structures and Magnetic Properties; Nova Science Publishers, Inc.: Hauppauge, NY, USA, 2010. 
37. Handzlik, G.; Magott, M.; Arczyński, M.; Sheveleva, A.M.; Tuna, F.; Baran, S.; Pinkowicz, D. Identical anomalous Raman relaxation exponent in a family of single ion magnets: Towards reliable Raman relaxation determination? Dalton Trans. 2020, 49 , 11942-11949. [CrossRef]

38. SHELXTL-2013/4, Bruker Analytical X-Ray Instruments; Sheldrick, G.M. (Ed.) Bruker Analytical X-ray Systems, Inc.: Madison, WI, USA, 2013.

39. Diamond 4.5.0; Crystal Impact GbR; Crystal Impact: Bonn, Germany, 2018.

40. CrystalMaker 8.7.5; CrystalMaker Software Ltd.: Oxford, UK, 2013.

41. Bain, G.A.; Berry, J.F. Diamagnetic Corrections and Pascal's Constants. J. Chem. Educ. 2008, 85, 532-536. [CrossRef] 